\title{
Effectiveness of Natural Apophyseal Glides Versus Grade I and II Maitland Mobilization in Non Specific Neck Pain
}

\author{
Shahzada Iftikhar Hussain, ${ }^{1}$ Ashfaq Ahmad, ${ }^{2}$ Freaha Amjad, ${ }^{3}$ Tariq Shafi, ${ }^{4}$ Hassan Anjum Shahid ${ }^{5}$
}

\begin{abstract}
Background and Introduction: Mechanical malfunction of cervical spine is the usual cause of neck pain. Even though varied procedures have been suggested for maximizing neck movements and decreasing neck pain but mobilization of joints has been validated the most efficacious technique. The outcome of two manual therapy procedures i.e. Mulligan natural apophyseal glides and grade I and II Maitland mobilezation in non-specific neck pain to reduce pain and recovery of function had been assimilated in this recent research.
\end{abstract}

Methods: It was a single blinded randomized control

Conflict of Interest: No

Funding Source: No

Hussain S.I. ${ }^{1}$

Physiotherapy Senior lecturer

University of Lahore, Pakistan

Ahmad A. ${ }^{2}$

Assistant Professor / HOD of Physiotherapy Department

University of Lahore

Amjad F. ${ }^{3}$

Physiotherapy Senior lecturer

University of Lahore, Pakistan

Shafi T. ${ }^{4}$

Physiotherapist, Shalamar Hospital, Lahore

Shahid H.A. ${ }^{5}$

Assistant Professor / HOD Physiotherapy Department Imperial University Lahore clinical trial. 50 patients having NSNP were chosen via simple number table and arranged into two groups as guided by CONSORT (Consolidated Standards of Reporting Trials) guidelines. In group A Mulligan mobilization NAGS was applied and in group B Grade 1 and II Maitland mobilizations were applied. Both groups also received conventional therapy Ultrasonic Therapy (ITO US - 100) in Continuous mode, frequency $1 \mathrm{MHz}$, intensity $1.0 \mathrm{~W} / \mathrm{cm}^{2}$ with $70 \%$ for $5 \mathrm{minu}-$ tes and Short wave diathermy (ENRAF NONIUS Curaplus 970) in co-planer, continuous mode, frequency $27.12 \mathrm{MHz}$, wavelength 11 meters, for $15 \mathrm{minu}-$ tes. Therapy was offered 4 times a week for absolute 4 weeks. Pain, disability were evaluated by NPRS (Numeric pain rating scale), NDI (neck disability index) scale. Assessment was done at 0 , after 2 and 4 weeks of treatment. Independent-Sample $\mathrm{T}$ Test was applied. Level of significance was set at $0.05 \%$ rank.

Results: The results exhibited that The P-value for NDI in group A using Mulligan mobilization NAGS was 0.018 and for NPRS was 0.014 after four weeks of treatment which was less than the level of significance 0.05 . So Mulligan mobilization NAGS was more effective than Grade 1 and II Maitland mobilization in nonspecific neck pain to decrease pain and restoration of function.

Conclusion: It was concluded that mobilization of Mulligan i.e. NAGS was more effective compared with mobilization of Maitland in Grade 1 and II in progressing NPRS and NDI scores in sufferers with nonspecific neck pain.

Key Words: Nonspecific neck pain, Maitland mobilization, Mulligan mobilization, NPRS, NDI. 


\section{Introduction}

The extremely habitual and aching musculoskeletal ailment is neck pain. Point prevalence ranges from $6 \%$ to $22 \%$ and up to $38 \%$ of the elderly population, while lifetime prevalence ranges from $14.2 \%$ to $71 \%$. For the predominance of neck complaints there is no absolute pathology or any malfunctioning of anatomical structures. For this reason they are termed as non-specific. This creates a deficient of a gold standard assessment for NSNP (nonspecific neck pain). From this perspective NSNP is mainly diagnosed on the basis of clinical grounds, provided there are no features to suggest a specific or more serious condition. The symptoms of NSNP are similar to those of whiplash associated disorders grade I and II but there is no traumatic event involved. ${ }^{1}$

The risk factors for NSPN are old age, gender, smoking, low social support and working atmosphere is not supporting, high job demands like heavy labor and previous history of lumbo-sacral and cervical pains. $^{2}$

There are different interventional strategies to manage nonspecific neck pain like conservative and non-conservative ways comprising, pain management with medication intervention, and surgery. For the conservative management of cervical diseases and for the cervical surgeries physical therapy is crucial feature for rehabilitation of patients. This involves strengthening of muscles, stabilization exercises and flexibility, manipulation, procedures of mechanical traction and mobilization. ${ }^{3}$

Evidences of manual therapy for nonspecific neck pain in literature are worthwhile. For the management of nonspecific neck pain and pain relief for neck diseases manual mobilizations techniques are frequently used and seems to be productive. ${ }^{4}$

Many studies have been conducted regarding the effectiveness of the Maitland and Mulligan mobilizations in nonspecific neck pain but the gap in previous literature is that there is no study designed yet to evaluate and compare the particular techniques of Mulligan mobilization NAGS and grade I, II Maitland mobilization in nonspecific neck pain . Hence, the core aim of this study was to collate the Mulligan mobilization technique NAGS and grade I, II Maitland mobilization for treating the nonspecific neck pain.

Rationale of this research was to give an evidence based selection of utmost productive method in the process of clinical decision making, while managing the patients with nonspecific neck Pain. Current study had addressed the relative effectuality of previously described treatment techniques which were missing in previous studies. So that physiotherapists could treat the patients with a better procedure. The primary outcomes measures were pain intensity and functional ability.

\section{Material and Methods}

Comparative experimental single blinded, randomized control clinical trials study design was used. By using simple random sampling technique as guided per CONSORT guidelines a data of 50 patients was collected who fulfilled the inclusion and exclusion standards and split into two equal sub groups each containing 25 patients. This study was single-centered and data was collected from Physiotherapy Department Shalamar Hospital, Lahore.

\section{Sample Selection Criteria}

\section{Inclusion Criteria}

- All referred patients having chief illness of NSNP.

- Both male and female patients, aged between 18 to 45 years.

- All the participators joining the investigation must have main complaint of NSNP that is present in the specified area (it should be located anywhere in the region that is bordered by superior nuchal line present superiorly, and on inferior there is a fictitious line that passes the tip of first thoracic spinous process and sagittal planes approaching the lateral boundary of the cervical is present laterally).

- The neck pain occurrence should be lesser than 3 months span followed by minimum of thirty days that were pain free.

- The severity of pain should be adequate (on a numerical pain rating scale it should be higher than 2 out of 10) for approving a clinically benefitcial effect to be exhibited. ${ }^{5}$

\section{Exclusion Criteria}

- Musculoskeletal systemic disease (e.g. rheumatoid arthritis etc).

- Neck pain due to serious spinal pathology (e.g. tumor, dislocation, infection) or other specific causes. 
- Patients with history of osteoporosis and diagnosed with thoracic outlet syndrome, cervical rib, cervicogenic headache and vertigo.

- The previous history of whiplash trauma, prior to 6 weeks of inspection.

- Patients with h/o fractures of cervical or thoracic spine

- Any former h/o cervico-thoracic surgery. ${ }^{6}$

\section{Data Collection Procedure}

Fifty patients who completed the selection criteria were enrolled in this study. Written informed consent was taken from every individual participating in this study prior to performing any examination. Allocation of patients in two groups had been by random number table to assure external validity as per CONSORT guidelines 2010.

Group A was treated with Mulligan mobilization NAGS group B with Grade 1 and Grade II Maitland mobilization. Mobilization was given by the researcher colleague. Both groups received the conventional therapy, which remained same throughout the study. The conventional therapy included Ultrasonic Therapy (ITO US - 100) in Continuous mode, frequency $1 \mathrm{MHz}$, intensity $1.0 \mathrm{~W} / \mathrm{cm}^{2}$, with $70 \%$ for 5 minutes and Short wave diathermy (ENRAF NONIUS Curaplus 970) in co-planer, continuous mode, frequency 27.12 MHz, wavelength 11 meters, for 15 minutes.

Group A received conventional therapy plus Mulligan mobilization NAGS with $2-3$ hertz (for less than 6 repetitions) in 3 sets. Group B was also managed by traditional therapy plus oscillatory movements of Maitland grade I, II that was given with $2-3 \mathrm{hertz}$ for total of 60 seconds. Commencing with grade I repeats there was afterwards raise in gradual manner up to grade II mobilizations. Treatment frequency was
4 times a week. The duration of treatment was 4 weeks in both groups, while each subject remained in the study for 4 weeks. Subjects were examined at baseline, by the end of 2nd week and 4th week (follow-up).

Pain intensity was appraised by Numeric pain rating scale (NPRS) $(r=0.95){ }^{7}$ The Neck Disability Index (NDI) was used to measure functional ability $(r=0.94-0.99){ }^{8}$

All this information was gathered by using a predesigned questionnaire and neck disability index.

Confounding variables were controlled by randomization and restriction methods. All treatment was applied by single handed for controlling bias.

If there was any drop out of patient during study, proforma of that patient was filled through intention to treat analysis method which was set as $15 \%$.

\section{Results}

Entire statistical calculations were prepared by SPSS 20 version. The qualitative variables were elaborated by formulating tables, proportions and charts of frequencies and variables of quantitative nature by means and Standard Deviation (SD). To find out the comparative difference of variables having quantitative nature was measured by applying Independent Sample $\mathrm{T}$ test. $\mathrm{P}$-value $\leq 0.05$ was considered as significant.

\section{Interpretation for NPRS}

Group A (Mulligan mobilization NAGS), showed mean pain score on NPRS before treatment 4.8000 $(\mathrm{SD}=2.43242)$, where as in group B (Maitland mobilization in Grade I \& II) showed mean score on NPRS before treatment $4.6400(\mathrm{SD}=2.30723)$. After four weeks of treatment group A showed mean score on NPRS as $.7600(\mathrm{SD}=1.09087)$, whereas patients in

Table 1: Group Statistics for NPRS.

\begin{tabular}{|l|c|c|c|c|c|}
\hline & Study Groups & $\mathrm{N}$ & Mean & Std. Deviation & Std. Error Mean \\
\hline \multirow{2}{*}{ NPRS before treatment } & Mulligan & 25 & 4.8000 & 2.43242 & .48648 \\
\cline { 2 - 6 } & Maitland & 25 & 4.6400 & 2.30723 & .46145 \\
\hline \multirow{2}{*}{ NPRS after 2 week } & Mulligan & 25 & 2.1200 & 1.45258 & .29052 \\
\cline { 2 - 6 } & Maitland & 25 & 3.0000 & 2.25462 & .45092 \\
\hline \multirow{2}{*}{ NPRS after 4 week } & Mulligan & 25 & .7600 & 1.09087 & .21817 \\
\cline { 2 - 6 } & Maitland & 25 & 2.0800 & 2.34379 & .46876 \\
\hline
\end{tabular}


Table 2: Independent Samples Test.

\begin{tabular}{|c|c|c|c|c|c|c|c|c|c|c|}
\hline & & $\begin{array}{r}\text { Leve } \\
\text { Equalit }\end{array}$ & $\begin{array}{l}\text { est for } \\
\text { Variances }\end{array}$ & \multicolumn{7}{|c|}{ t-test for Equality of Means } \\
\hline & & \multirow{2}{*}{$\mathrm{F}$} & \multirow{2}{*}{ Sig. } & \multirow{2}{*}{$\mathrm{T}$} & \multirow{2}{*}{ df } & \multirow{2}{*}{$\begin{array}{l}\text { Sig. (2- } \\
\text { tailed) }\end{array}$} & \multirow{2}{*}{$\begin{array}{c}\text { Mean } \\
\text { Difference }\end{array}$} & \multirow{2}{*}{$\begin{array}{l}\text { Std. Error } \\
\text { Difference }\end{array}$} & \multicolumn{2}{|c|}{$\begin{array}{l}95 \% \text { Confidence Interval } \\
\text { of the Difference }\end{array}$} \\
\hline & & & & & & & & & Lower & Upper \\
\hline \multirow{2}{*}{$\begin{array}{l}\text { NPRS } \\
\text { before } \\
\text { treatment }\end{array}$} & $\begin{array}{l}\text { Equal } \\
\text { variances } \\
\text { assumed }\end{array}$ & .004 & .951 & .239 & 48 & .812 & .16000 & .67052 & -1.18818 & 1.50818 \\
\hline & $\begin{array}{l}\text { Equal } \\
\text { variances } \\
\text { not assumed }\end{array}$ & & & .239 & 47.867 & .812 & .16000 & .67052 & -1.18827 & 1.50827 \\
\hline \multirow{2}{*}{$\begin{array}{l}\text { NPRS } \\
\text { after } 2 \\
\text { week }\end{array}$} & $\begin{array}{l}\text { Equal } \\
\text { variances } \\
\text { assumed }\end{array}$ & 4.876 & .032 & -1.641 & 48 & .107 & -.88000 & .53641 & -1.95852 & .19852 \\
\hline & $\begin{array}{l}\text { Equal } \\
\text { variances } \\
\text { not assumed }\end{array}$ & & & -1.641 & 40.996 & .109 & -.88000 & .53641 & -1.96330 & .20330 \\
\hline \multirow{2}{*}{$\begin{array}{l}\text { NPRS } \\
\text { after } 4 \\
\text { week }\end{array}$} & $\begin{array}{l}\text { Equal } \\
\text { variances } \\
\text { assumed }\end{array}$ & 13.706 & .001 & -2.553 & 48 & .014 & -1.32000 & .51704 & -2.35958 & -.28042 \\
\hline & $\begin{array}{l}\text { Equal } \\
\text { variances } \\
\text { not assumed }\end{array}$ & & & -2.553 & 33.932 & .015 & -1.32000 & .51704 & -2.37084 & -.26916 \\
\hline
\end{tabular}

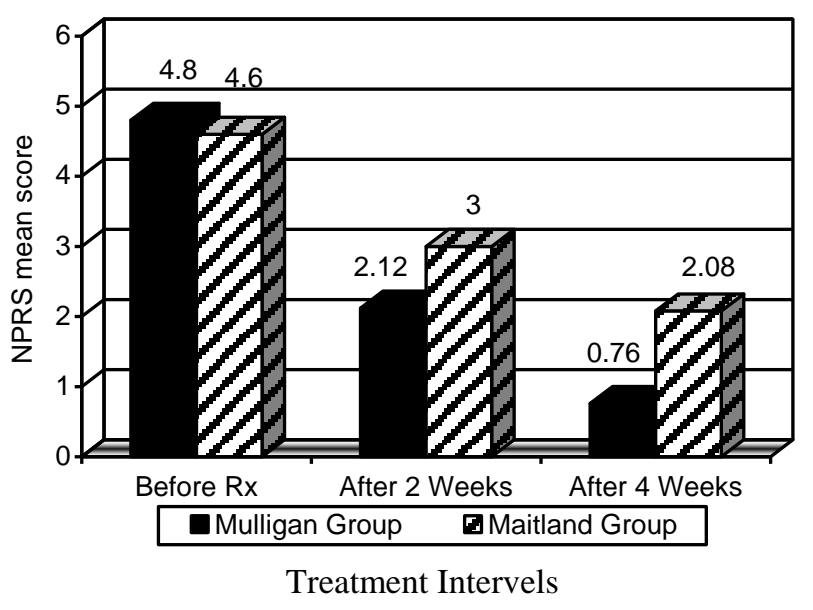

Graph 1: NPRS Mean Score Groups Comparison.

group B showed mean score on NPRS after four weeks of treatment as $2.0800(\mathrm{SD}=2.34379)$. For NPRS the results indicate that there was averagely notable variation among the mean NPRS post treatment score and NPRS pre treatment score $(\mathrm{t}=-2.553, \mathrm{p}=.014)$. As $\mathrm{p}=.014$ was less than $\mathrm{p}=.05$ so we reject our null hypothesis and accept research hypothesis. Both gro- ups confirmed that there was absolute betterment in their intensity of pain $(P<0.014)$, at 4 week follow-up points $(P<0.014)$. So Mulligan natural apophyseal glide mobilization technique is more effective than Grade I \& II Maitland mobilization in nonspecific neck pain.

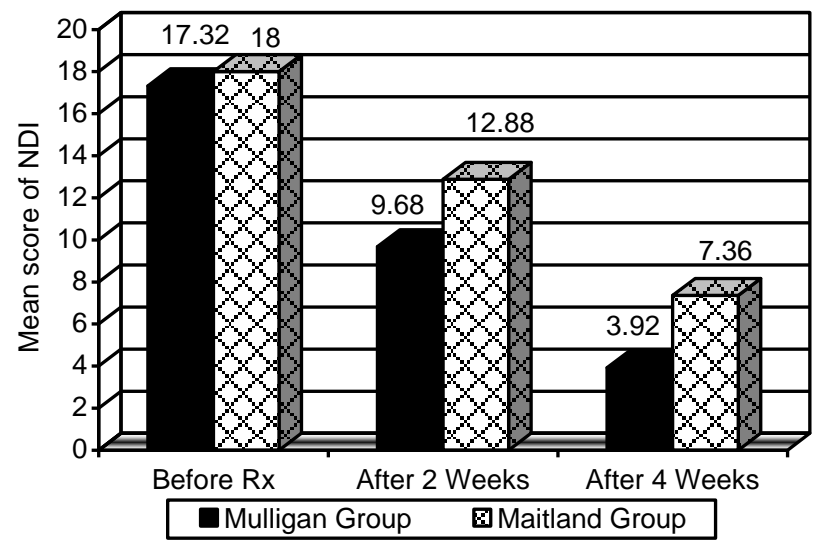

Treatment Intervels

Graph 2: NDI Mean Score Groups Comparison. 
Table 3: Group Statistics for NDI.

\begin{tabular}{|l|c|c|c|c|c|}
\hline & Study Groups & $\mathrm{N}$ & Mean & Std. Deviation & Std. Error Mean \\
\hline \multirow{2}{*}{ NDI before treatment } & Mulligan & 25 & 17.3200 & 7.88310 & 1.57662 \\
\cline { 2 - 6 } & Maitland & 25 & 18.0000 & 8.38650 & 1.67730 \\
\hline \multirow{2}{*}{ NDI after 2 week treatment } & Mulligan & 25 & 9.6800 & 5.97718 & 1.19544 \\
\cline { 2 - 5 } & Maitland & 25 & 12.8800 & 7.63392 & 1.52678 \\
\hline \multirow{2}{*}{ NDI after 4 week treatment } & Mulligan & 25 & 3.9200 & 3.34066 & .66813 \\
\cline { 2 - 5 } & Maitland & 25 & 7.3600 & 6.15684 & 1.23137 \\
\hline
\end{tabular}

Table 4: Independent Samples Test.

\begin{tabular}{|c|c|c|c|c|c|c|c|c|c|c|}
\hline & & \multicolumn{2}{|c|}{$\begin{array}{l}\text { Levene's Test for } \\
\text { Equality of Variances }\end{array}$} & \multicolumn{7}{|c|}{ t-test for Equality of Means } \\
\hline & & \multirow[t]{2}{*}{$\mathrm{F}$} & \multirow[t]{2}{*}{ Sig. } & \multirow[t]{2}{*}{$\mathrm{T}$} & \multirow[t]{2}{*}{ Df } & \multirow{2}{*}{$\begin{array}{l}\text { Sig. } \\
(2- \\
\text { tailed) }\end{array}$} & \multirow{2}{*}{$\begin{array}{c}\text { Mean } \\
\text { Difference }\end{array}$} & \multirow{2}{*}{$\begin{array}{l}\text { Std. Error } \\
\text { Difference }\end{array}$} & \multicolumn{2}{|c|}{$\begin{array}{l}95 \% \text { Confidence } \\
\text { Interval of the } \\
\text { Difference }\end{array}$} \\
\hline & & & & & & & & & Lower & Upper \\
\hline \multirow{2}{*}{$\begin{array}{l}\text { NDI } \\
\text { before } \\
\text { treatment }\end{array}$} & $\begin{array}{l}\text { Equal } \\
\text { variances } \\
\text { assumed }\end{array}$ & .152 & .698 & -.295 & 48 & .769 & -.68000 & 2.30197 & -5.30842 & 3.94842 \\
\hline & $\begin{array}{l}\text { Equal } \\
\text { variances not } \\
\text { assumed }\end{array}$ & & & -.295 & 47.817 & .769 & -.68000 & 2.30197 & -5.30888 & 3.94888 \\
\hline \multirow{2}{*}{$\begin{array}{l}\text { NDI after } \\
2 \text { week } \\
\text { treatment }\end{array}$} & $\begin{array}{l}\text { Equal } \\
\text { variances } \\
\text { assumed }\end{array}$ & 1.435 & .237 & -1.650 & 48 & .105 & -3.20000 & 1.93911 & -7.09883 & .69883 \\
\hline & $\begin{array}{l}\text { Equal } \\
\text { variances not } \\
\text { assumed }\end{array}$ & & & -1.650 & 45.388 & .106 & -3.20000 & 1.93911 & -7.10464 & .70464 \\
\hline \multirow{2}{*}{$\begin{array}{l}\text { NDI after } \\
4 \text { week } \\
\text { treatment }\end{array}$} & $\begin{array}{l}\text { Equal } \\
\text { variances } \\
\text { assumed }\end{array}$ & 8.548 & .005 & -2.455 & 48 & .018 & -3.44000 & 1.40095 & -6.25680 & -.62320 \\
\hline & $\begin{array}{l}\text { Equal } \\
\text { variances not } \\
\text { assumed }\end{array}$ & & & -2.455 & 37.004 & .019 & -3.44000 & 1.40095 & -6.27859 & -.60141 \\
\hline
\end{tabular}

\section{Interpretation for NDI}

Group A (Mulligan mobilization NAGS), showed mean pain score on NDI before treatment 17.3200 $(\mathrm{SD}=7.88310$ ), where as in group B (Maitland mobilization in grade I \& II) showed mean score on NDI before treatment 18.0000 ( $\mathrm{SD}=8.38650)$. After four weeks of treatment group A showed mean score of neck pain disability index 3.9200 ( $\mathrm{SD}=3.34066)$, whereas patients in group B Maitland mobilization in grade I \& II, showed mean score of neck pain dis- ability index $7.3600(\mathrm{SD}=6.15684)$. The results indicated a statistically significant difference between the mean NDI post treatment score and NDI pre treatment score $(\mathrm{t}=-2.455, \mathrm{p}=.018)$. As $\mathrm{p}=.018$ is less than $\mathrm{p}=.05$ so we reject our null hypothesis and accept research hypothesis. So Mulligan natural apophyseal glide mobilization technique is more effective than Grade I \& II Maitland mobilization in nonspecific neck pain. 


\section{Discussion}

Purpose of this research was to conclude the comparative effectiveness of Mulligan natural apophyseal glides and grade I and II Maitland mobilization, for the treatment of nonspecific neck pain regarding reduction of pain and restoration of function. In the present research both of these mobilization techniques have been used as an intervention to treat the patients of nonspecific neck pain.

Patients with nonspecific neck pain were divided randomly into two groups. In 'group A' Mulligan mobilization technique i.e. NAGS was applied while in 'group B' Maitland mobilization technique Grade 1 and Grade II was applied.

Neck disability index and baseline questionnaire was used to assess the patient before and after treatment of two, four weeks. Neck disability index score was compared in both groups before and after treatment. Mean score of group A for NDI was 17.3200 and group B was 18.0000. Both mean scores showed that patients in group A and group B had approximated same disability. Group A mean score was decreased from 17.3200 to 3.9200 and group B score was decreased from 18.0000 to 7.3600 after four weeks of treatment. Both group showed decrease in mean score but group A had a significant decrease. So it proved that intervention given to group A was more effective than intervention given to group $\mathrm{B}$.

In this study, NPRS was also used to assess the patients before and after treatment of two and four weeks. Group A mean score was reduced from 4.8000 to .7600 and group B score was reduced from 4.6400 to 2.0800 after treatment. It also proved that group A improved more than group B. So Mulligan mobilization technique NAGS was proved more effective in reducing pain and improving neck disability index than Grade 1 and Grade II Maitland mobilizations in nonspecific neck pain.

For representing the results statistically Independent Sample T Test was used. The outcome demonstrated a statistically notable difference amid the mean NDI post treatment score and NDI pre-treatment score $(\mathrm{t}=-2.455, \mathrm{p}=.018)$. As $\mathrm{p}=.018$ was less than $\mathrm{p}=.05$ so we reject our null hypothesis and research hypothesis.

Independent Sample $\mathrm{T}$ Test was also performed for NPRS score. The results indicated that there was a statistically significant conflict between the mean NPRS post treatment score and NPRS pre-treatment score $(\mathrm{t}=-2.553, \mathrm{p}=.014)$. As $\mathrm{p}=.014$ was less than $\mathrm{p}=.05$ so we rejected our null hypothesis and accept alternative hypothesis. So Mulligan mobilization technique NAGS proved more effective in reducing pain and improving neck disability index than Grade 1 and Grade II Maitland mobilizations.

Our conclusion conform formerly issued trials on patients having nonspecific neck pain.

Similar study was conducted by Rajesh Gautam et al in 2014 Comparison of Maitland and Mulligan Mobilization in improving neck pain range of motion (ROM) and disability. This study validated that Mulligan mobilization was more beneficial in improving neck pain, disability and ROM. ${ }^{9}$

In 2011 Deepak, Kumar had conducted a study to determine the effectiveness of Mulligan NAGS in neck pain and stiffness. The results of this study proved that NAGs is a effective mobilization technique for providing faster and prolong outcomes in decreasing pain and improving range of motions with functional activities in patients having pain and stiffness of neck area. ${ }^{10}$

In 2014, Ali et al, studied the efficiency of sustained natural apophyseal glides with and without isometric exercise training in nonspecific neck pain. They discovered that patients having NSNP when treated with sustained natural apophyseal glides techniques along with isometric exercise had more decrease in pain and advancement in function ability as comparing to those patients who were treated with just sustained natural apophyseal glides techniques. ${ }^{11}$

Exelby contends that by improving the glides of zygoapophyseal joints by applying NAGS and SNAGS will enhance the spinal movement as zygoapophyseal joints guide the spine. ${ }^{12}$

The benefit of the Mulligan mobilization showed a marked decline in NDI scores and NPRS score in support of existing result, w.r.t the research, the medical effectiveness of Mulligan's mobilizations techniques have been settled for amending joint function, with a number of hypotheses for its cause and effect. More recent researches have proved further methods that include the hypoalgesic and sympathetic nervous system excitation effects. ${ }^{13}$

Hence from the accessible studies and the statistical results of data obtained following the treatment deduces that, "Mulligan mobilization technique NAGS is a better than Grade 1 and Grade II Maitland mobilization technique in improving Pain, and disability. 


\section{Conclusion and Recommendation}

Mulligan natural apophyseal glide mobilization technique for the cure of nonspecific neck pain has confirmed to be more helpful in aiding pain, and fixing neck impairment in patients having nonspecific neck pain than Grade I \& II Maitland mobilization. The results of this clinical analysis aid in explaining the employment of manual physical therapy in patients with nonspecific neck pain. For the true effect of this regimen, future exploration should comprise well-planned randomized control trials with extended treatment duration, longer patient follow-up periods, larger sizes of samples, and self - reported measures of function.

\section{References}

1. Giannoula Tsakitzidis WD, PT, MT, PhD. Non-specific Neck Pain and Evidence - Based Practice. European Scientific Journal, January 2013; 9 (3).

2. McLean SM, May S, Klaber - Moffett J, Sharp DM, Gardiner E. Risk factors for the onset of non-specific neck pain: a systematic review. Journal of epidemiology and community health, 2010; 64 (7): 565-72.

3. Urrehman SS, Ali A, Sibtain F. The efficacy of sustained natural apophyseal glides with and without isometric exercise training in non-specific neck pain, 2014.

4. Leaver AM, Maher CG, Herbert RD, Latimer J, McAuley JH, Jull G, et al. A randomized controlled trial comparing manipulation with mobilization for recent onset neck pain. Archives of physical medicine and rehabilitation, 2010; 91 (9): 1313-8.
5. Andrew M Leaver*1 KMR, Christopher G Maher1, Jane Latimer1 RDH, Gwendolen Jull2 and James H McAuley1. Efficacy of manipulation for non-specific neck pain. BMC Musculoskeletal Disorders. 26 February $2007 ; 8$ : 18: 2-5.

6. Cleland JA CJ, Fritz JM, Whitman JM, Eberhart SL. Development of a clinical prediction rule for guiding treatment of a subgroup of patients with neck pain. Use of thoracic spine manipulation, exercise, and patient education Physical Therapy, 2010; 1 (87): 9-23.

7. Dijk JF, Kappen TH, Wijck AJ, Kalkman CJ, Schuurmans MJ. The diagnostic value of the numeric pain rating scale in older postoperative patients. Journal of clinical nursing, 2012; 21 (21-22): 3018-24.

8. McCarthy M, Grevitt M, Silcocks P, Hobbs G. The Reliability and Validity of the Vernon and MIOR Neck Disability Index (NDI). Journal of Bone and Joint Surgery, British Volume, 2012; 94 (SUPP II): 86-.

9. Gautam R, Dhamija JK, Puri A, Trivedi P, Sathiyavani D, Nambi G, et al. Comparison of Maitland And Mulligan Mobilization In Improving Neck Pain, ROM and Disability. Int J Physiother Res. 2014; 2 (3): 561-6.

10. Deepak K. A study on the efficacy of mulligan concept in cervical spine pain and stiffness: Guru Nanak Dev University, 2011.

11. Ali A, Shakil-ur-Rehman S, Sibtain F. The efficacy of sustained natural apophyseal glides with and without isometric exercise training in non-specific neck pain. Pakistan journal of medical sciences, 2014; 30 (4): 872.

12. Exelby L. Peripheral mobilisations with movement. Manual therapy, 2012; 1 (3): 118-26.

13. Hing W, Bigelow R, Bremner T. Mulligan's mobilisation with movement: a review of the tenets and prescription of MWMs. NZJ Physiother. 2008; 36 (3): 14464. 